\title{
Research on Prevention and Management of Substation Operation
}

\author{
Li Bo, Zhang Wenguang, Zhao Hengxin, Wang Chuang, Cao Huiyan, Jin Jing, Zhan \\ Shuguang, Hao Wenfeng, Zheng Jiming, Wang Tianhao
}

Fushun Power Supply Company, Liaoning Electric Power Company Limited, State Grid, China

Keywords: Electrical operation; Safety management; Electrical accident prevention; Control measures

\begin{abstract}
With the rapid improvement of the economic level of China, people have put forward higher demands for the safe operation of the power grid. The safety of substation operation is directly related to the safe and reliable power supply of the power network. Therefore, in the operation of electric power enterprises, the safety management of electrical operation should be improved, and the prevention and management of electrical accidents should be actively done, so as to eliminate the hidden dangers in electrical work.
\end{abstract}

\section{Introduction}

Substation operation is the first line of safe power supply in power grid. The operation condition of substation is directly related to the safety and stability of the whole power supply area. This puts forward strict requirements for substation workers. It is necessary for substation workers to strictly control the safety management of substation power in their work, pay attention to the load capacity of substation equipment, strengthen inspection, maintenance and inspection. They should also conduct a timely investigation of the potential safety risks in the operation of the substation. The author analyzes the safety management in the operation of substation, so that transformer workers can better prevent the occurrence of electrical accidents in their work.

\section{Hidden trouble in substation operation}

\subsection{Hidden trouble of operation}

Substation workers are the front-line personnel in the operation of substation, and play a very important role in the substation work. Therefore, the electric power enterprises should strictly require the personal quality and theoretical knowledge of the substation workers. Substation personnel can work according to the standard, which is directly related to the stability and safety of substation operation. In actual substation operation, the substation workers need to operate more transformer equipment. Therefore, in the long-term power transformation operation, the spirit is inevitably slacking, and the safety operation consciousness is gradually fading, which is easy to cause operational errors. Finally, the electrical accident occurred.

\subsection{Hidden trouble of transformer equipment}

Due to the frequent use of electrical equipment in substation operation, it is inevitable for electrical equipment to appear circuit aging and mechanical fatigue in long term work. In addition, some quality problems may exist in the electrical equipment itself, as well as problems caused by equipment failures caused by staff negligence, and equipment inspection and maintenance work are not in place, which has laid a serious safety hazard for the whole substation operation. It may eventually lead to an electrical accident.

\subsection{Hidden troubles in management work}

The management of substation operation is also one of the important reasons that affect the safety of substation operation. There are many problems in the management of substation operation in many electric power enterprises, and the safety system of substation operation is not perfect. The 
lack of safety consciousness and the lack of maintenance and management system of substation operation equipment are also the important factors leading to electrical safety accidents in substation operation.

\section{Causes of transformer accident and hidden trouble}

Through the past analysis of substation accidents, the following main causes of the accidents can be summarized:

\subsection{Operational errors of substation operators}

During the operation of the substation, most of the electrical accidents are caused by human operation errors, which is often due to the long term single operation of the substation operators, who believe that they have mastered a considerable amount of experience in the operation of electrical equipment. Thus neglecting the importance of safe operation, blindly think that they are highly skilled and bold, thus slackening safety awareness, resulting in careless operation mistakes. They often regret after the event, regret that they did not have serious and meticulous operation. If they had always kept the safety of production in mind and formed a good working habit and attitude, how can that lead to a serious electrical accident?

One of the causes of the accident is the wrong operation of the operator, but on the other hand, there are also the problems that some electric power enterprises do not carefully check the gate when recruiting electrical operators. Place people with incomplete knowledge of power operations or lack of professional integrity into important operational positions.

\subsection{Electrical equipment is out of repair}

It is also a cause of transformer accidents. In the actual work, some substations have great problems in management. For example, many substation equipment has been seriously aging, or even problems, but not timely repair or replacement. Generally speaking, every substation should make records or data supervision on its own power equipment operation status. When the equipment has a problem, the relevant personnel record, and then find specialized personnel to carry out maintenance. If the equipment problem is big, we should replace the new power equipment immediately to maintain the good operation of the power system and prevent the occurrence of the transformer accident.

\subsection{Lack of transfer check in substation operation}

Handover inspection is also one of the factors causing electrical accidents. As a result of the unpredictability of equipment failure, there is occasionally such a situation: when the equipment is operated by the switching operator, the equipment is running normally, and when the personnel are switching the posts, the equipment will be checked for the operation status of the equipment based on the inertia of thinking. The equipment malfunction after the shift, but the personnel fail to notice the abnormal situation in time, and finally lead to the electrical accident.

\section{Management measures of Safety production in Substation Operation}

From the above, it can be seen that the main factors causing electrical accidents in substation operation can be summed up into human factors and equipment factors. In order to reduce the probability of electrical accident and eliminate the hidden trouble in electric production in time, some safety management methods and management measures can be obtained by synthesizing the above two kinds of factors.

\subsection{Improving the business level of electric operators in substation operation}

The staff in the operation of substation should not only master the relevant knowledge in the field of electric power operation, but also pay attention to the cultivation of their own comprehensive qualities, which include work quality, consciousness quality and psychological 
quality. Quality of work is in the work, can maintain at all times serious, cautious and safe first work attitude, it must regard safety production and standardized operation as the basic working principles. Consciousness quality is to pay attention to the abnormal situation in the operation of electrical equipment at all times, cultivate good fault detection ability, and put safety consciousness first. Psychological quality, electrical operation of substation operation belongs to a special type of work, has a greater risk, therefore, in the event of electrical failure, the staff should maintain a good attitude, actively solve the problem, in the event of an electrical accident, it is necessary to stabilize the state of mind and take effective measures to prevent the further expansion of the accident so as to reduce the loss and influence caused by the electrical accident.

\subsection{Strengthening the propaganda of security and improve Electrical production system}

The electric power enterprise should strengthen the safety production propaganda to the electrical staff regularly, to prevent the loss of safety awareness due to long-term work. Electric power enterprises can use blackboard newspaper, enterprise manual, safety slogan, accident image data, safety briefing and so on to carry out safety publicity and education to the staff, so as to improve the sense of responsibility for the production safety of the substation operators, and hang up safety use rules of electric equipment in the vicinity of the electrical equipment. At the same time, the electric power enterprise should formulate scientific and reasonable electric production system and the related accountability system according to the actual situation of the enterprise. Thus, the responsibility of electrical production can be implemented to individuals, and the main electrical operators can always receive safety encouragement, then reducing the probability of electrical accidents caused by human factors.

\subsection{Pay attention to skills training and facilities maintenance on a regular basis}

With the development of society and the renewal of new national standards, electrical operators are required to keep their professional skills up to date. Therefore, enterprises should regularly organize relevant technical personnel to carry out skills training, or conduct technical lectures and study of new regulations, so that substation operators can master the latest information and knowledge within their responsibilities. In order to improve the working quality of substation operators, reduce the incidence of errors.

Enterprises should also set up related electrical facilities technical groups, regularly maintain and maintain the substation facilities, and timely find out the failure caused by the facilities in operation. And take appropriate measures to repair, resolutely eliminate electrical equipment with disease operations. In order to improve the safety and quality of electrical facilities, the old electrical facilities should be eliminated and updated.

\section{Conclusion}

The operation of substation operation directly affects the safe operation of power supply system, so operation and maintenance in substation operation is very important. Due to the complexity of the whole power system and the high technical requirements, the probability of electrical accidents in the operation of substation is also high. Therefore, it is necessary to strengthen the safety consciousness of the operators and increase the maintenance and management system of electrical equipment in power transformer operation, in order to minimize the incidence of electrical accidents.

\section{Reference}

[1] Wu Lingli. Discussion on Safety Management and Accident Prevention Strategy in Substation Operation [J]. Science and Technology Entrepreneurs, 2012(19):106-109.

[2] Liu Xiaochun, Zhu Mingyang. Discussion on Safety Management and accident Prevention of Substation Operation [J]. Science and Technology Innovation and Application, 2012(33):175-176. [3] $\mathrm{Yu}$ Lingyong, Wang dividend. On the management of substation operation safety and the prevention of accidents [J].Guangdong Science and Technology, 2012(23):80-81. 